\title{
Experimental study on the influence of water pressure on acoustic emission entropy characteristics during the siltstone tunnel water inrush
}

\author{
Yanbo Zhang ${ }^{1,2, a}$, Guangyuan $\mathrm{Yu}^{1,2, \mathrm{~b}^{*}}$ Peng Liang ${ }^{1,2, \mathrm{c}}$ Xiangxin Liu ${ }^{1,2, \mathrm{~d}}$ \\ Baozhu Tian ${ }^{1,2, e}$ \\ ${ }^{1}$ College of Mining Engineering, North China University of Science and Technology, Tangshan, \\ Hebei 063009, China; ${ }^{2}$ Hebei Province mining industry develops with safe technology priority \\ laboratory, Tangshan 063009, China; \\ áfzdn44444@163.com, ${ }^{\mathrm{b}} 386071340 @ q q . c o m,{ }^{c} 466874131 @ q q . c o m,{ }^{d}$ liuxiangxin9@163.com \\ 'tianbaozhu1111@xina.com
}

Keywords: water pressure; siltstone; water inrush; acoustic emission; entropy

Abstract. An experiment is carried out to simulate siltstone tunnel water inrush with both the water pressure and no water pressure by biaxial rigid servo-controlled system. The PCI-2 acoustic emission(AE) system produced by American physical acoustics corporation is used to collect data of the AE in the process of water inrush synchronously. Study on the influence of water pressure on water inrush process and the entropy of AE combined with the water inrush process. The result shows that the water pressure change face seepage model, and advanced the penetration time and water inrush time of tunnel face; The water pressure changed the entropy evolution model and fluctuation interval before water inrush occurred, the entropy increase slowly, the whole loading process in the range of $1 \sim 1.8$ before the water inrush occurred under the conditions of without water pressure; In the conditions of water pressure the entropy jump increase, the whole loading process in the range of 1.0 3.0 before the water inrush occurred. The results provide an experimental basis for the application of $\mathrm{AE}$ to the monitoring and early warning of tunnel water inrush.

\section{Introduction}

Mine water disaster is one of the important factors which influence the safety of mines, according to statistics, water damage in the serious coal mine accidents is second only to the major hazard of gas explosion $^{[1]}$. The flood disaster in the death toll after gas accidents, ranking the second place; in frequency following the gas and roof accidents, ranking the third place in china ${ }^{[2]}$. So give enough give enough attention on the flood forecast, which is especially important for the tunneling roadway of coal mine water inrush disaster prediction.

The $\mathrm{AE}$ of rock under the action of external force, and the $\mathrm{AE}$ characteristics can reflect the development of the rock cracks in the stress process, the stress state and damage of rock in the process of stress ${ }^{[3]}$. Scholars have done a lot of research on the AE characteristics of mine water inrush. In document [2], the AE characteristics of coal under different stress rates and different moisture state were carried out, and according to the difference of the AE spectrum, the experimental system for online monitoring of the water inrush from the mine water inrush was carried out. In document [4], the $\mathrm{AE}$ characteristics of granite under the condition of water pressure are studied, and the AE signal characteristic frequency bands of granite fracture and water seepage are obtained. The numerical simulation experiment of the AE monitoring hydraulic fracturing is carried out in [5], the law of the whole process of crack initiation, water seepage and water inrush from the cracks of the overlying rock is summarized.

In recent years, with the increase of mining depth mine construction was often in high water pressure, so the study of the impact on the process of water inrush and the AE of water pressure is very important for the prediction of water inrush. Based on the above analysis, this paper take mine construction often encountered siltstone of tunnel water inrush simulation experiment, study pressure 
on water inrush process and $\mathrm{AE}$ entropy values characteristic influence. The results lay the foundation of $\mathrm{AE}$ in mine water inrush prediction.

\section{Research project}

Experimental equipment Load device selection RLW - 3000 servo press, 3D-SY type electric pressure test pressure pump, The AE data acquisition using type PCI-2 AE system, between the probe and the surface of rock AE coupled with Vaseline. Test site as in figure 1.
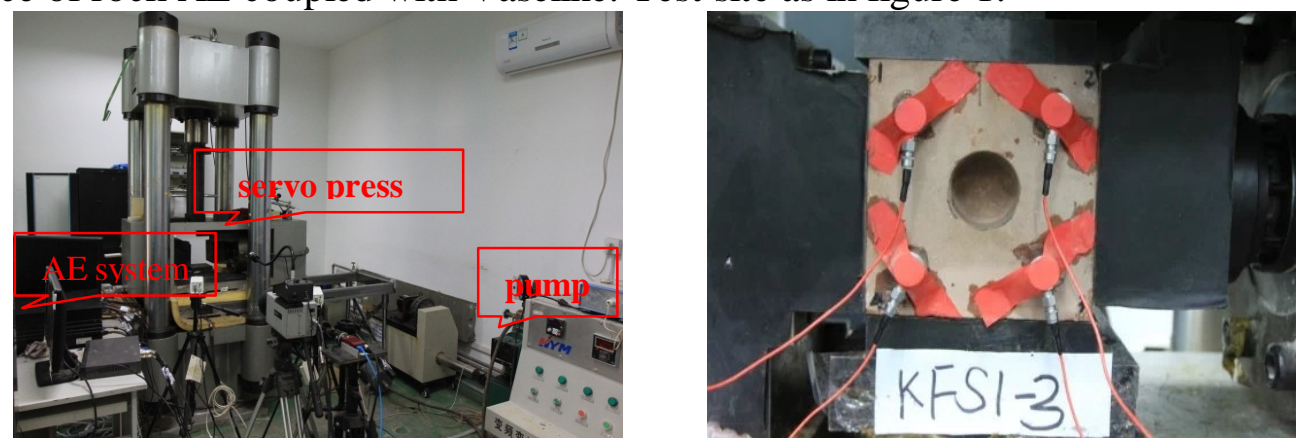

Fig. 1 Experimental field

Sample preparation The siltstones are made of the size of $150 \mathrm{~mm} \times 150 \mathrm{~mm} \times 150 \mathrm{~mm}$. The drilling machine is used to drill a hole in the center of the sample, and the depth is $45 \mathrm{~mm}$, and the depth is $90 \mathrm{~mm}$, and then at the same relative surface, the depth of the hole is $50 \mathrm{~mm}$, and the diameter of the same circular hole is the observation hole, reserved $10 \mathrm{~mm}$ thickness between the two holes as a face. Carefully polished the surface of the load carried by the experimental procedure.

Experimental procedure The specimens were divided into two groups, one group in the deep hole filled with water and sealing the hole, without pressure, another group water injection in the hole and $0.5 \mathrm{MPa}$ water pressure. Loading mode for biaxial loading, the lateral pressure is applied to the $200 \mathrm{kN}$ to remain constant, and the axial load of the $0.3 \mathrm{~mm} / \mathrm{min}$ until the specimen water inrush.

\section{Analysis of the experimental result}

Analysis of the process of siltstones tunnel water inrush It can be found that the water pressure has a great influence on the process of siltstones tunnel water inrush. In the condition of pressure, when the axial load to a certain value, tunnel face began to appear seepage points followed by seepage sites to the seepage point as the center spread rapidly to the tunnel face, with the increase of the load, the face of infiltration water increases gradually, With the increase of the load, the face of infiltration water increases gradually, continue to loading tunnel surface infiltration water showing two kinds of model, a tunnel face in the rupture of seepage quantity the number of increase, another tunnel face in the rupture of seepage remained basically unchanged. Continue to loading tunnel surface infiltration water showing two kinds of evolution model, a tunnel face in the rupture of seepage quantity multiple increase, another tunnel face in the rupture of seepage remained basically unchanged, tunnel face burst, water influx of roadway when got to peak load; In the condition of without water pressure, the axial load to a certain value, the tunnel face was wet, with the increase of the load, tunnel face infiltration content increased gradually; In the condition of without water pressure, the axial load to a certain value, the tunnel face was wet, with the increase of the load, tunnel face infiltration content increased gradually, and continue loading the tunnel face rupture, water influx to the tunnel.

From table 1, the water pressure makes the siltstone tunnel face seepage and water inrush ahead of time, this demonstrates that pressure reduces siltstone tunnel face threshold value of subcritical crack expansion. In the conditions of water pressure due to the tunnel face blocking water leads to accelerated penetration, when the axial load reaches a certain value, the rapid expansion of the crack, The seepage system in the siltstone was destroyed, Osmotic stress has been temporarily unloaded, the movement of water in rock mass is no longer flow form, but along with the tunnel face a rout of the fracturing channel flow movement, so it is under water pressure water inrush form more violent. 
Table 1 Sample seepage evolution schedule

\begin{tabular}{lccccc}
\hline $\begin{array}{c}\text { Sample } \\
\text { number }\end{array}$ & $\begin{array}{c}\text { water } \\
\text { pressure }\end{array}$ & $\begin{array}{c}\text { Seepage time } \\
\text { /s }\end{array}$ & $\begin{array}{c}\text { Average } \\
\text { seepage time } \\
\text { /s }\end{array}$ & $\begin{array}{c}\text { Water } \\
\text { bursting } \\
\text { time/s }\end{array}$ & $\begin{array}{c}\text { Average time } \\
\text { of water } \\
\text { inrusht/s }\end{array}$ \\
\hline KFS0-1 & No & 850 & & 918 & \\
KFS0-2 & 504 & 701 & 975 & 962 \\
KFS0-3 & 749 & 36 & & 992 & \\
\hline KFS1-1 & Yes & 10 & 18 & 803 & 794 \\
KFS1-2 & 8 & & 694 & \\
KFS1-3 & & 8 & & 695 & \\
\hline
\end{tabular}

Analysis of the $\mathrm{AE}$ entropy characteristics during the whole process of siltstone tunnel water inrush Entropy is a system is determined in the chaos after the chaotic degree measure, it is the key index of quantitative evaluation of system stability degree. Specific calculation process is as follows: an AE signal is $x(n), n=1 \sim N$, hist is used to block the assignment of function $X(n)$ in the first place, then the data of each block is calculated, and find the corresponding probability, the final use of information entropy formula. In this paper, the expression of the information entropy is:

$$
\mathrm{H}(\mathrm{x})=-\sum_{i=1}^{n} P_{i} \ln P_{i} \text {. }
$$

Figure 2 (a), (b) were siltstone specimens load, entropy - time curve in the conditions of without water pressure and with water pressure. Under the two conditions near the water inrush occurred before the entropy increased trend, the entropy smaller increase, and slow growth in the condition of without water pressure, the entropy was jumping increased, the increasing range is bigger, after a period of time remained at a relatively high level of entropy in the condition of water pressure.

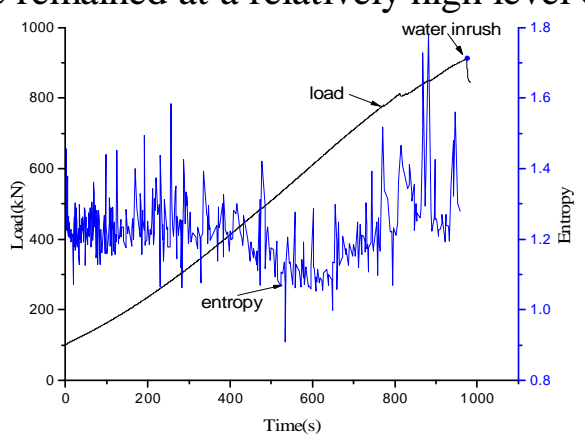

KFS0-2

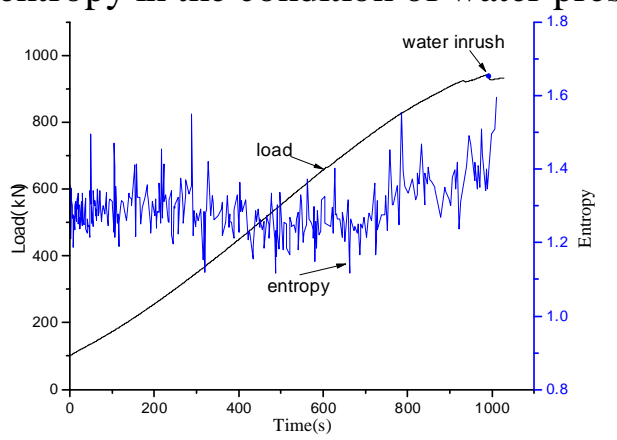

KFSO-3

(a) without water pressure

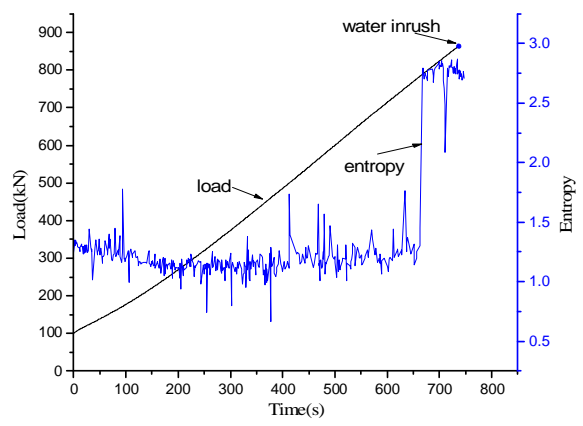

KFS $1-2$

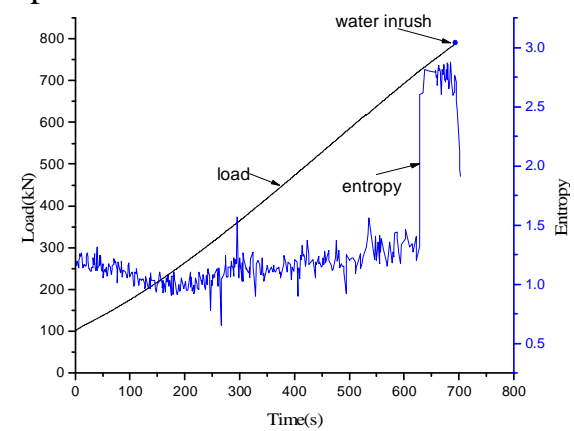

KFS1-3

(b) with water pressure

Fig.2 Load-entropy-time curves

In the condition of without water pressure, the face water inrush is mainly caused by the axial load, the tunnel face first appeared a small break before water inrush occurred, with the increase of load small rupture gradually evolved into a big burst, the tunnel face degree crack expanding disorder gradually increased, the entropy shows slowly increasing trend; In the condition of water pressure, the tunnel face water inrush is mainly caused by axial loading and water pressure interaction, through 
experimental phenomena can be known the water infiltration changes a little before the tunnel water inrush under water pressure, this was due to the pressure made the tunnel face crack expansion speed up, resulting the evolution of micro cracks is not obvious before water inrush occurred, so entropy show jumping increase. So the increase of entropy can be regarded as the precursor of water inrush.

As can be seen from Figure 2, water pressure has a great influence on the entropy fluctuation range. The entropy changes from 1.0 to 1.8 range in the condition of without water pressure, However in the condition of water pressure the entropy in the range of 1.0 to 3.0. It indicates the existence of pressure made the entropy range increase, and improve the maximum entropy of the whole process of water inrush. This means that the system has a high degree of disorder in the process of rock breaking under the condition of water pressure, that is the disorder of internal crack propagation in rock is high.

\section{Summary}

(1) The process of siltstone tunnel water inrush is obviously influenced by water pressure, the pressure change in the presence of the tunnel face seepage pattern and make water inrush ahead of time.

(2) The water pressure changed the entropy evolution model before water inrush. The acoustic emission entropy increase slowly before water inrush under water pressure, and the acoustic emission entropy jumping increase before water inrush under without water pressure, this can be used as the precursor of water inrush.

(3) The water pressure was increased the entropy fluctuation range in the whole process of water inrush. The entropy changes from 1.0 to 1.8 range in the condition of without water pressure, However in the condition of water pressure the entropy is in the range of 1.0 to 3.0.

\section{Acknowledgements:}

The national natural science foundation of China $(51374088,51174071)$,natural science foundation of Hebei Province(E2012209047).

\section{References}

[1] Wu Qiang. Progress, problem and prospects of prevention and control technology of mine water and reutilization in China[J]. Journal of China Coal Society,2014(5):795-804.

[2] Tang Shoufeng,Tong Minming,Qin Haipeng,et al. The acoustic emission experiment system of rock outburst in water inrush[J]. Journal of Mining \& Safety Engineering, 2010(3):429-437.

[3] Seto M, Nag D K, Vutukuril V S. Acoustic emission in coal and sandstone under triaxial compressive stress condition[A]. In : Rockbursts and Seismicity in Mines[C]. Rotterdam:A. A. Balkema,1997. 427- 431.

[4] Zhang Yanbo,Chen Binbin,Jing Guanghui. Research of infrared radiation and acoustic emission feature of granite during fracturing and water seepage process[J]. Metal Mine, 2013(4):65-68.

[5] Kang Zhiqiang,Zhou Yunfei,Qin Haimin. Experimental study and numerical simulation of hydraulic fracturing of rock based on acoustic emission monitoring[J]. Industrial Minerals \& Processing, 2012(6):23-26. 